ARTICLE

DOI: $10.1038 / s 41467-017-01259-z$

OPEN

\title{
Bottom-up precise synthesis of stable platinum dimers on graphene
}

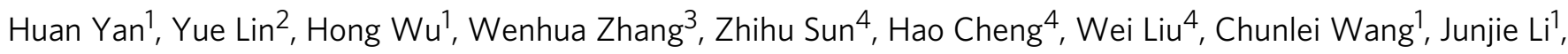
Xiaohui Huang1, Tao Yao (1) ${ }^{4}$, Jinlong Yang ${ }^{1,2}$, Shiqiang Wei ${ }^{4}$ \& Junling Lu (1) 1,2,3,5

Supported metal clusters containing only a few atoms are of great interest. Progress has been made in synthesis of metal single-atom catalysts. However, precise synthesis of metal dimers on high-surface area support remains a grand challenge. Here, we show that $\mathrm{Pt}_{2}$ dimers can be fabricated with a bottom-up approach on graphene using atomic layer deposition, through proper nucleation sites creation, $\mathrm{Pt}_{1}$ single-atom deposition and attaching a secondary $\mathrm{Pt}$ atom selectively on the preliminary one. Scanning transmission electron microscopy, $x$-ray absorption spectroscopy, and theoretical calculations suggest that the $\mathrm{Pt}_{2}$ dimers are likely in the oxidized form of $\mathrm{Pt}_{2} \mathrm{O}_{x}$. In hydrolytic dehydrogenation of ammonia borane, $\mathrm{Pt}_{2}$ dimers exhibit a high specific rate of $2800 \mathrm{~mol}_{\mathrm{H} 2} \mathrm{~mol}_{\mathrm{Pt}}{ }^{-1} \mathrm{~min}^{-1}$ at room temperature, 17 - and 45-fold higher than graphene supported Pt single atoms and nanoparticles, respectively. These findings open an avenue to bottom-up fabrication of supported atomically precise ultrafine metal clusters for practical applications.

\footnotetext{
${ }^{1}$ Department of Chemical Physics, University of Science and Technology of China, Hefei, Anhui 230026, China. ${ }^{2}$ Hefei National Laboratory for Physical Sciences at the Microscale, University of Science and Technology of China, Hefei, Anhui 230026, China. ${ }^{3}$ CAS Key Laboratory of Materials for Energy Conversion, University of Science and Technology of China, Hefei, Anhui 230026, China. ${ }^{4}$ National Synchrotron Radiation Laboratory, University of Science and Technology of China, Hefei, Anhui 230029, China. ${ }^{5}$ Collaborative Innovation Center of Chemistry for Energy Materials (iChEM), University of Science and Technology of China, Hefei 230026, China. Huan Yan and Yue Lin contributed equally to this work. Correspondence and requests for materials should be addressed to S.W. (email: sqwei@ustc.edu.cn) or to J.L. (email: junling@ustc.edu.cn)
} 
S upported metal catalysts are among the most important categories of heterogeneous catalysts in many reactions including chemical upgrading, automobile exhaust treatment, Fischer-Tropsch synthesis, biomass conversions, and many other processes ${ }^{1-7}$. Decreasing metal particle size is desirable for improving metal utilization, since catalytic reactions take place on the surface of metal nanoparticles (NPs). When a metal cluster contains only a few metal atoms, it could have a discrete energy band structure, tightly correlated with the number of metal atoms. Changing one atom in the ultrafine cluster might largely alter the electronic structure and drastically change its catalytic properties. Such atom-dependent catalytic behaviors have been successfully demonstrated by the model catalysts of mass-selected metal clusters, which were fabricated by soft landing of massselected ions from their physical vapor under ultrahigh vacuum conditions $^{8-14}$. However, such complicated approach is only limited to model catalyst studies and is not applicable to highsurface area supports for practical applications.

Recently, synthesis of supported metal single-atom catalysts (SACs) has been extensively explored and a number of successful examples have been demonstrated ${ }^{15-23}$. Nonetheless, synthesis of atomically precise ultrafine metal clusters, such as dimers, on high-surface area supports, remains a grand challenge. The decisive limitation is the lack of precise control over the aggregation process, which often causes metal NPs formation with a broad size distribution. Protecting metal clusters with a strong ligand can certainly inhibit metal aggregation to a large extent, such as in the case of thiolate-protected Au magic clusters ${ }^{24}$. However, these strong protective ligands typically poison the metal clusters, and decrease their catalytic activities considerably ${ }^{25-30}$. Alternatively, Gates et al. demonstrated that precisely defined iridium and rhodium clusters were achieved by grafting the corresponding carbonyl complexes with a specific number of metal atoms onto oxide supports ${ }^{31-33}$. But the success is limited. As a consequence, a general bottom-up approach to synthesize atomically precise metal clusters on high-surface area supports is still missing. Atomic layer deposition (ALD) relies on two sequential self-limiting surface reactions at the molecular level, which are separated by inert gas purging ${ }^{34-36}$. This unique character makes ALD possible to bottom-up construct catalytic materials on a high-surface area substrate uniformly and precisely $y^{37-39}$.

Here, we show that $\mathrm{Pt}_{2}$ dimers can be bottom-up fabricated on a graphene support by depositing Pt on phenol-related oxygen anchor sites atom-by-atom in a sequential manner using Pt ALD. The dominant presence of isolated $\mathrm{Pt}_{1}$ single atoms and $\mathrm{Pt}_{2}$ dimers in the corresponding samples were confirmed by both aberration-corrected high-angle annular dark-field scanning transmission electron microscopy (HAADF-STEM) and X-ray absorption fine structure spectroscopy (XAFS). Their structures were determined through a combination of density function theory (DFT) calculations and XAFS spectra simulations. In hydrolysis of ammonia borane (AB) for hydrogen generation, graphene supported $\mathrm{Pt}_{2}$ dimers $\left(\mathrm{Pt}_{2} /\right.$ graphene) exhibited a striking activity, which is $\sim 17$ - and 45 -fold higher than that of graphene supported $\mathrm{Pt}_{1}$ single atoms and $\mathrm{Pt} \mathrm{NPs}$, respectively. Compared to $\mathrm{Pt}_{1}$ single atoms and $\mathrm{Pt} \mathrm{NPs}$, the decreased adsorption energies of both $\mathrm{AB}$ and $\mathrm{H}_{2}$ molecules on $\mathrm{Pt}_{2}$ dimers are likely the major reason for the high activity. More importantly, the $\mathrm{Pt}_{2}$ dimers were stable under the current reaction condition and in the inert environment at below $300^{\circ} \mathrm{C}$.

\section{Results}

Synthesis and morphology of $\mathrm{Pt}_{\mathbf{1}} / \mathrm{graphene}$ and $\mathrm{Pt}_{2} /$ graphene. Based on our recent strategy ${ }^{22}$, the nucleation sites of isolated phenols or phenol-carbonyl pairs suggested by Shenoyl et $\mathrm{al}^{40}$. for Pt ALD were first created on pristine graphene nanosheets through acid oxidation followed by high-temperature thermal reduction, as illustrated in the schematic model in Fig. 1. The reduced graphene oxide support was defect-rich multilayered graphene films with a thickness of about a few nanometers (Supplementary Fig. 1). It had a surface area of $570 \mathrm{~m}^{2} / \mathrm{g}$. Next, Pt ALD was performed on the graphene support by alternately exposing trimethyl(methylcyclopentadienyl)-platinum(IV) $\left(\mathrm{MeCpPtMe}_{3}\right)$ and molecular $\mathrm{O}_{2}$ at $250^{\circ} \mathrm{C}$. The self-limiting surface reactions between $\mathrm{MeCpPtMe}_{3}$ and the support ensure nucleation of one $\mathrm{MeCpPtMe}_{3}$ molecule on one phenol-related nucleation site during the saturated $\mathrm{MeCpPtMe}_{3}$ exposure (Supplementary Fig. 2). It should be noted that Pt nucleation on graphene defect sites, such as edges and line defects, was inhibited at $250^{\circ} \mathrm{C}$, although it is possible at $300^{\circ} \mathrm{C}$ (Supplementary Table 1$)^{41}$. A similar temperature effect on inhibiting metal ALD on oxides was also observed by Elam et al ${ }^{42}$. Next, the ligands were removed through a combustion reaction during the $\mathrm{O}_{2}$ exposure step ${ }^{43-45}$ and $\mathrm{Pt}_{1}$ single atoms are formed (denoted as $\mathrm{Pt}_{1} /$ graphene).

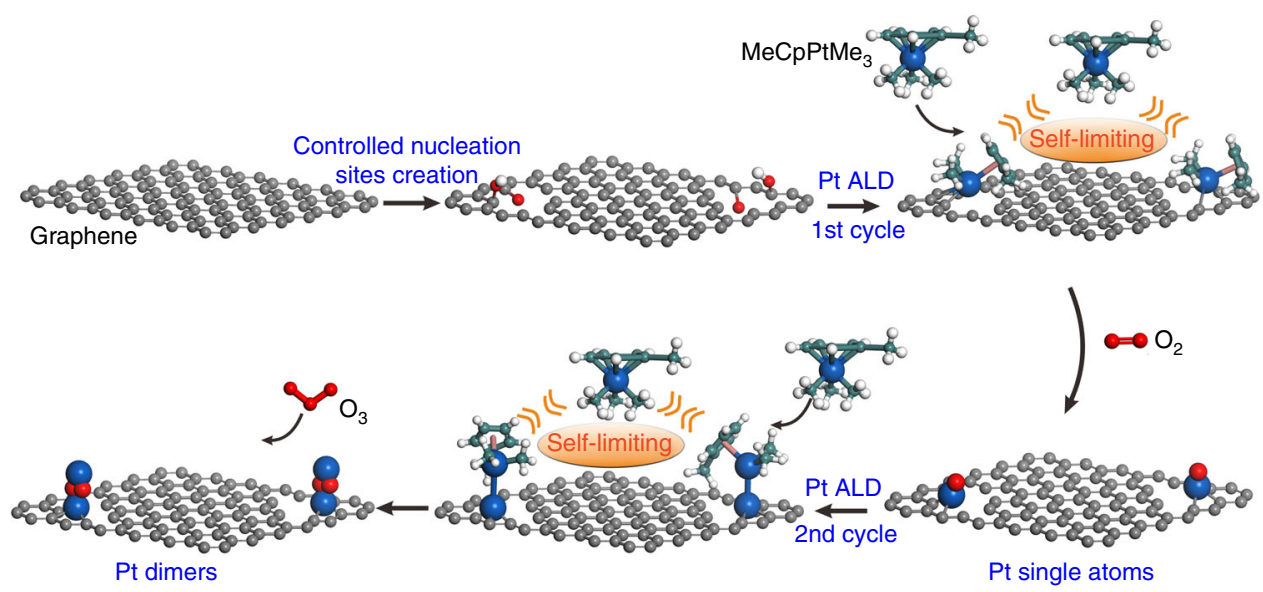

Fig. 1 Schematic illustration of bottom-up synthesis of dimeric $\mathrm{Pt}_{2} /$ graphene catalysts. Controlled creation of isolated anchor sites on pristine graphene; one cycle of Pt ALD on the anchor sites for Pt single atoms formation by alternately exposing $\mathrm{MeCpPtMe}_{3}$ and molecular $\mathrm{O}_{2}$ at $250{ }^{\circ} \mathrm{C}$; second cycle of $\mathrm{Pt}$ ALD on the $\mathrm{Pt}_{1} /$ Graphene to selectively deposit the secondary Pt atoms on the preliminary ones for $\mathrm{Pt}_{2}$ dimers formation at $150{ }^{\circ} \mathrm{C}$. The balls in cyan, white, red, and blue represent carbon, hydrogen, oxygen, and platinum while the ball in gray represents carbon atoms in the graphene support 
Next, the formed $\mathrm{Pt}_{1}$ single atoms was further utilized as nucleation sites for anchoring the secondary $\mathrm{MeCpPtMe}_{3}$ molecule in the following cycle. Again, the steric hindrance between $\mathrm{MeCpPtMe}_{3}$ molecules restricts chemisorbing one $\mathrm{MeCpPtMe}_{3}$ molecule only on one isolated $\mathrm{Pt}_{1}$ atom. However, we noticed that a considerable amount of $\mathrm{Pt}$ NPs were formed after two successive cycles of Pt ALD at $250^{\circ} \mathrm{C}$ (denoted as $2 \mathrm{cPt}$ /graphene, Supplementary Fig. 3 ). Therefore, the deposition temperature was decreased to $150{ }^{\circ} \mathrm{C}$ for the second ALD cycle to avoid any metal aggregation. Meanwhile, ozone $\left(\mathrm{O}_{3}\right)$, a stronger oxidizing regent was utilized to remove the ligand efficiently to form $\mathrm{Pt}_{2}$ dimers $\left(\mathrm{Pt}_{2} / \text { graphene) (Fig. } 1\right)^{46}$. The formed $\mathrm{Pt}_{1}$ single atoms and $\mathrm{Pt}_{2}$ dimers are expected to be in the oxidized forms, since they were exposed to $\mathrm{O}_{2}$ and $\mathrm{O}_{3}$ during synthesis, respectively.

Aberration-corrected HAADF-STEM measurements were carried out to investigate the morphologies of the single-atom $\mathrm{Pt}_{1} /$ graphene and dimeric $\mathrm{Pt}_{2} /$ graphene catalysts. Compared to the naked graphene (Supplementary Fig. 1), HAADF-STEM images illustrated that one cycle of Pt ALD on the graphene support at $250{ }^{\circ} \mathrm{C}$ resulted in a formation of atomically dispersed $\mathrm{Pt}_{1}$ atoms without presence of any visible clusters or NPs (Fig. 2a-c, and Supplementary Fig. 4). These $\mathrm{Pt}_{1}$ single atoms were well isolated from each other with a distance $>2 \mathrm{~nm}$ in average, which is significantly larger than the effective diameter of the $\mathrm{MeCpPtMe}_{3}$ molecule of $\sim 0.96 \mathrm{~nm}^{47}$, confirming the steric effect during synthesis. Similar to our recent study of $\mathrm{Pd}_{1}$ singleatom growth on graphene $e^{22}$, we found that complete removal of other oxygen-contained functional groups, such as carboxyl groups, from graphene by carefully tuning the reduction temperature and time, is the key to eliminate any Pt clusters or NPs formation (Supplementary Fig. 5). These findings suggest that metal atoms anchored on carboxyl groups have a general weak interaction with the graphene support, thus aggregate aggressively to larger metal NPs under the ALD conditions, in line with literature ${ }^{48}$.

After performing another cycle of $\mathrm{Pt} \mathrm{ALD}$ on $\mathrm{Pt}_{1} /$ graphene at $150{ }^{\circ} \mathrm{C}$ ( $\mathrm{Pt}_{2} /$ graphene), $\mathrm{Pt}_{2}$ dimers were dominantly formed along with a certain number of $\mathrm{Pt}_{1}$ single atoms (Fig. 2d-f, and Supplementary Fig. 6), where neither Pt clusters nor NPs were observed. Very interestingly, we noticed that $\mathrm{Pt}_{2}$ dimers frequently rotated by specified angles of 30,60 , and $90^{\circ}$ under the electron beam during STEM measurements and then split into two isolated $\mathrm{Pt}_{1}$ atoms (see more details in Supplementary Figs. 7-9). Such characteristic rotations might be related with the geometry of the graphene support and the size of carbon defect by considering the aforementioned $\mathrm{Pt}_{2}$ dimer structure (Supplementary Fig. 10). This observation provides strong evidence of the presence of $\mathrm{Pt}_{2}$ dimers rather than the projection coincidence of two isolated $\mathrm{Pt}_{1}$ atoms at different $\mathrm{Z}$ positions. Statistical analysis of more than 80 pairs of $\mathrm{Pt}_{2}$ dimers showed a $\mathrm{Pt}-\mathrm{Pt}$ distance of $0.30 \pm 0.02 \mathrm{~nm}$ for $\mathrm{Pt}_{2}$ dimers (Fig. $2 \mathrm{~g}$ ), which is significantly longer than the $\mathrm{Pt}-\mathrm{Pt}$ bond in $\mathrm{Pt}$ bulk. This indicates that the $\mathrm{Pt}_{2}$ dimers are in the oxidized form as expected.

To step-wise elucidate the selective deposition of secondary $\mathrm{Pt}$ atom onto the preliminary ones for the formation of $\mathrm{Pt}_{2}$ dimers in the second ALD cycle, a set of control experiments were further performed using inductively coupled plasma-atomic emission spectroscopy (ICP-AES). First, the influence of the Pt precursor ligand on the second Pt ALD cycle was examined. In this case, half cycle of Pt ALD was executed on the graphene support by performing the $\mathrm{MeCpPtMe}_{3}$ pulse step only (denoted as $\mathrm{MeCpPtMe/graphene)} \mathrm{at} 250^{\circ} \mathrm{C}$. After that, the $\mathrm{ALD}$ reactor was cooled to near room temperature and half amount of the $\mathrm{MeCpPtMe/graphene} \mathrm{sample} \mathrm{was} \mathrm{taken} \mathrm{out} \mathrm{of} \mathrm{reactor} \mathrm{for} \mathrm{ICP-}$ AES analysis; while the rest of the sample was put back to the
ALD reactor quickly to perform the second cycle (Pt-MeCpPtMe/ graphene) at $150{ }^{\circ} \mathrm{C}$. In nine independent trials, the ICP-AES results showed that the ratio of the Pt loadings of Pt-MeCpPtMe/ graphene to those of the corresponding MeCpPtMe/graphene were all very close to one (Fig. $2 \mathrm{~h}$ ). Therefore, there was no additional $\mathrm{Pt}$ deposited on $\mathrm{MeCpPtMe/Graphene,} \mathrm{reflecting} \mathrm{the}$ saturated self-limiting reaction character of $\mathrm{ALD}^{34-36}$. Second, we found that exposure of pristine graphene to $\mathrm{O}_{2}$ at $250{ }^{\circ} \mathrm{C}$ did not cause any detectable Pt deposition either (Supplementary Table 1). This is very important to ensure that the oxygen pulse at $250{ }^{\circ} \mathrm{C}$ in the first ALD cycle did not create any additional nucleation sites. Taken together, the $\mathrm{Pt}_{1}$ single atoms formed on graphene, confirmed by HAADF-STEM in Fig. $2 \mathrm{a}-\mathrm{c}$, are the only nucleation sites for the following ALD cycle. It is worthy to note that $\mathrm{Pt}_{1}$ single atoms well isolated from each other could be crucial to make all the $\mathrm{Pt}_{1}$ single atoms accessible for chemisorbing the second $\mathrm{MeCpPtMe}_{3}$ molecule in the second ALD cycle without steric hindrance.

During the second ALD cycle, one $\mathrm{MeCpPtMe}_{3}$ molecule anchors on one $\mathrm{Pt}_{1}$ atom in the $\mathrm{Pt}_{1}$ /graphene sample due to the steric hindrance effect, which doubles the $\mathrm{Pt}$ loading. This was confirmed by the ratios of two for the Pt loadings of $\mathrm{Pt}_{2} /$ Graphene to $\mathrm{Pt}_{1} /$ graphene in nine independent trials (Fig. $2 \mathrm{i}$ and Supplementary Table 2), hence providing strong evidence of the formation of $\mathrm{Pt}_{2}$ dimers. The $\mathrm{Pt}_{1}$ single atoms observed in Fig. 2e and Supplementary Figs. 6-9 were likely formed by uncoupling of $\mathrm{Pt}_{2}$ dimers under the high flux electron beam during STEM measurements ${ }^{49}$. On the other hand, once Pt NPs were formed during ALD, the ratio of Pt loading of the two-ALD cycle sample to the one-cycle sample was apparently off from the stoichiometric value of two (Supplementary Table 2).

Performing an additional cycle on $\mathrm{Pt}_{2} /$ graphene to form $\mathrm{Pt}_{3}$ trimers might be possible. However, we noticed that the $\mathrm{O}_{3}$ in the second cycle can create additional nucleation sites on graphene. As a consequence, selective deposition was not achieved for the third cycle and resulted in a mixture of $\mathrm{Pt}_{1}, \mathrm{Pt}_{2}$ and $\mathrm{Pt}_{3}$. Therefore, we mainly focused on the $\mathrm{Pt}_{2}$ dimers in this work.

XAFS characterization and DFT calculations. Figure 3a shows the X-ray absorption near-edge structure (XANES) spectra of $\mathrm{MeCpPtMe} /$ graphene, $\mathrm{Pt}_{1}$ /graphene, and $\mathrm{Pt}_{2} /$ graphene at the $\mathrm{Pt}$ $L_{3}$-edge, along with $\mathrm{Pt}$ foil, $\mathrm{PtO}_{2}$, and $\mathrm{MeCpPtMe}_{3}$ as references. Evidently, the XANES white line peaks of these three samples $(11,567 \mathrm{eV})$ located at between $\mathrm{Pt}$ foil and $\mathrm{PtO}_{2}$, indicating that the $\mathrm{Pt}$ in $\mathrm{MeCpPtMe} /$ graphene, $\mathrm{Pt}_{1}$ single atoms, and $\mathrm{Pt}_{2}$ dimers were all in a similar oxidation state between $\mathrm{Pt}^{0}$ and $\mathrm{Pt}^{4+}$. The $\mathrm{MeCpPtMe}_{3}$ reference sample exhibits two well-resolved peaks at 1.62 and $1.99 \AA$ in the Fourier transformed (FT) $k^{3} \chi(k)$ curve in the real-space ( $R$-space) (Fig. $3 \mathrm{~b})$, assigned to the shorter Pt-C bonds (1.99-2.14 $\AA$ ) in the three $\mathrm{Pt}-\mathrm{Me}$ groups and longer $\mathrm{Pt}-\mathrm{C}$ bonds $(2.26-2.36 \AA$ ) in the $\mathrm{Pt}-\mathrm{MeCp}$ group, respectively (Supplementary Fig. 11a $)^{47,50}$. Apparently, the two split peaks in the $\mathrm{MeCpPtMe/graphene} \mathrm{curve} \mathrm{suggests} \mathrm{that} \mathrm{the} \mathrm{MeCp} \mathrm{group} \mathrm{stayed}$ on $\mathrm{Pt}$ in this sample. This observation is in line with both the experimental result of the formation of $\mathrm{MeCpPtMe}_{2}$ surface species on oxides ${ }^{43,51}$ and theoretical calculations where $\mathrm{MeCpPtMe}_{3}$ on epoxydated and hydroxylated graphene surfaces liberates either one or two methyl groups depending on the available surface groups ${ }^{52}$.

The first shell FT peak in the $\mathrm{Pt}_{1} /$ graphene spectrum had a higher intensity and slightly shifted to $1.65 \AA$, while the peak at $1.99 \AA$ disappeared. Clearly, the MeCp ligand was combusted off after the $\mathrm{O}_{2}$ exposure step at $250{ }^{\circ} \mathrm{C}$. The first shell peak is assigned to $\mathrm{Pt}-\mathrm{O}$ and/or $\mathrm{Pt}-\mathrm{C}$ coordinations. Similar to MeCpPtMe/graphene, a very weak peak at $2.4 \AA$ was visible in 

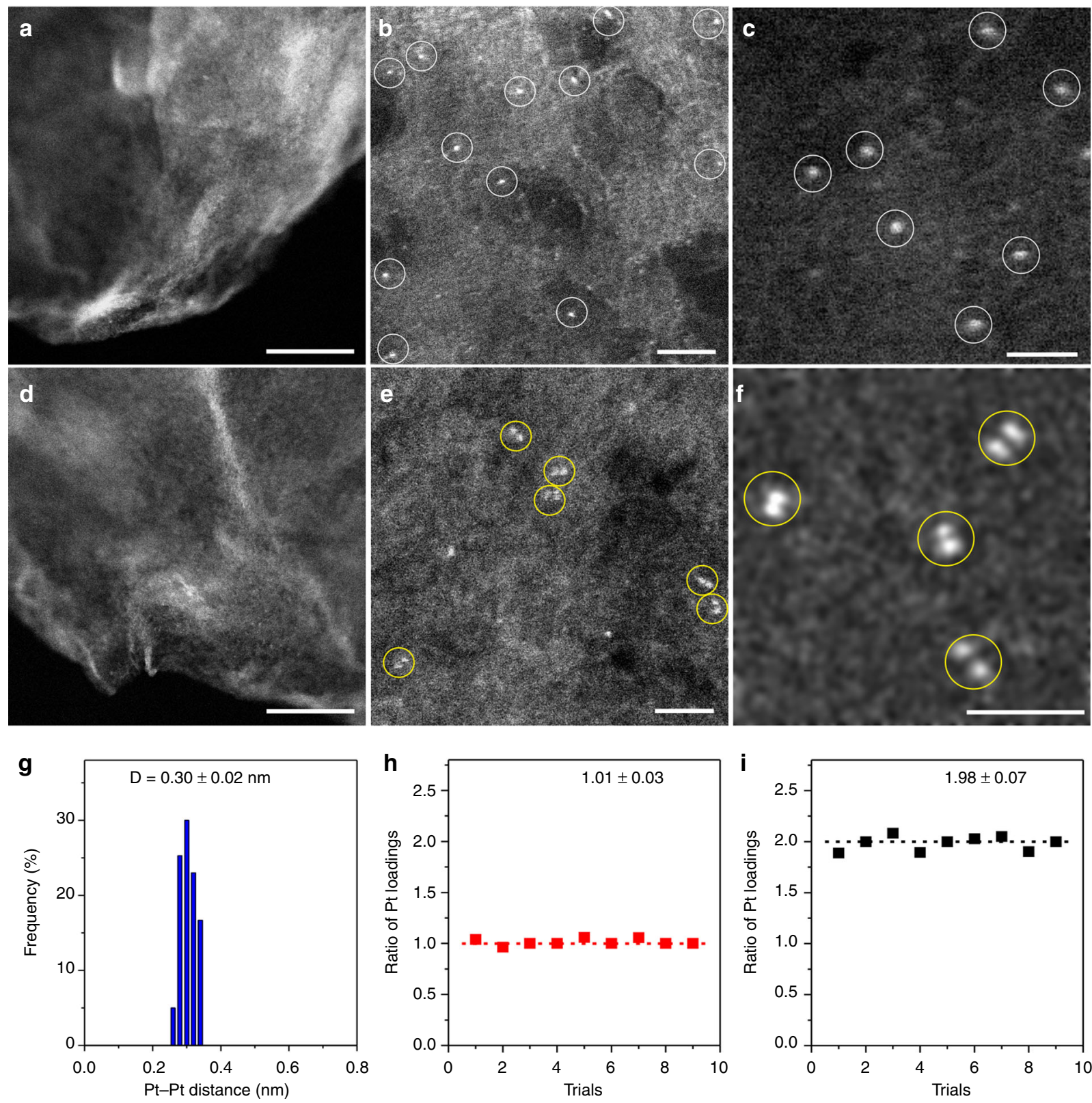

Fig. 2 Morphology of the single-atom $\mathrm{Pt}_{1} /$ graphene and dimeric $\mathrm{Pt}_{2} /$ graphene catalysts. Aberration-corrected HAADF-STEM images of Pt $/$ graphene (a-c) and dimeric $\mathrm{Pt}_{2} /$ graphene (d, e). Scale bars, $20 \mathrm{~nm}(\mathbf{a}, \mathbf{d}), 2 \mathrm{~nm}(\mathbf{b}, \mathbf{e})$, and $1 \mathrm{~nm}(\mathbf{c}, \mathbf{f})$. Pt single atoms in $\mathbf{b}$ and $\mathbf{c}$ and dimers in $\mathbf{e}$ and $\mathbf{f}$ are highlighted by white and yellow circles, respectively. $\mathbf{g}$ Statistical Pt-Pt distance in the observed $\mathrm{Pt}_{2}$ dimers. $\mathbf{h}$ The ratio of Pt loading of in Pt-MeCpPtMe/ graphene to that in $\mathrm{MeCpPtMe} /$ graphene, and $\mathbf{i}$ the ratio of $\mathrm{Pt}$ loading in $\mathrm{Pt}_{2} /$ graphene to that in $\mathrm{Pt}_{1} /$ graphene in nine independent trials determined by ICP-AES

the spectrum of $\mathrm{Pt}_{1} / \mathrm{graphene.} \mathrm{However,} \mathrm{this} \mathrm{peak} \mathrm{is} \mathrm{significantly}$ different from the Pt-Pt coordination peak (at $\sim 2.62 \AA$ ) in Pt foil, thus assigned to the second nearest $\mathrm{C} / \mathrm{O}$ neighbors of Pt. This suggests the absence of $\mathrm{Pt} \mathrm{NPs}$ in $\mathrm{Pt}_{1} /$ graphene, consistent with our STEM observation (Fig. 2a-c and Supplementary Fig. 4). The dimeric $\mathrm{Pt}_{2} /$ graphene sample showed a similar FT curve with $\mathrm{Pt}_{1} /$ graphene, implying a similar local $\mathrm{C} / \mathrm{O}$ coordinations in these two samples. In the $\mathrm{Pt}_{2} /$ graphene spectrum, there was no discernible peak for the $\mathrm{Pt}-\mathrm{Pt}$ coordination, suggesting the $\mathrm{Pt}_{2}$ dimers are in the oxidized form after the ozone exposure step at $150^{\circ} \mathrm{C}$.

Considering the difficulties in discriminating the $\mathrm{C} / \mathrm{O}$ neighbors by EXAFS fittings, we resorted to the combination of DFT calculations with EXAFS simulations to determine the optimized structures of these three samples. Here, a graphene support containing a carbon vacancy along with either isolated phenol group or phenol-carbonyl pairs ${ }^{40}$ was employed as the reduced graphene oxide surface. The structural models optimized by DFT calculations were further examined by EXAFS simulations.

Regarding the previous work ${ }^{52}$, the structures of $\mathrm{MeCpPtMe}_{2}$ and MeCpPtMe were both considered for the MeCpPtMe/ graphene sample (Supplementary Fig. 11). Compared to the $\mathrm{MeCpPtMe}_{3}$ molecule, the five Pt-C bonds in the Pt-MeCp group in these two structures both changed significantly. According to the EXAFS simulations for these two structures, $\mathrm{MeCpPtMe}$ bonded to the graphene support through two interfacial $\mathrm{O}$ atoms might be the promising structure for the $\mathrm{MeCpPtMe/graphene} \mathrm{sample} \mathrm{(Fig.} 3 \mathrm{c}$ and Supplementary Figs. 11b and 12). Compared to the spectrum of $\mathrm{MeCpPtMe}_{3}$, 

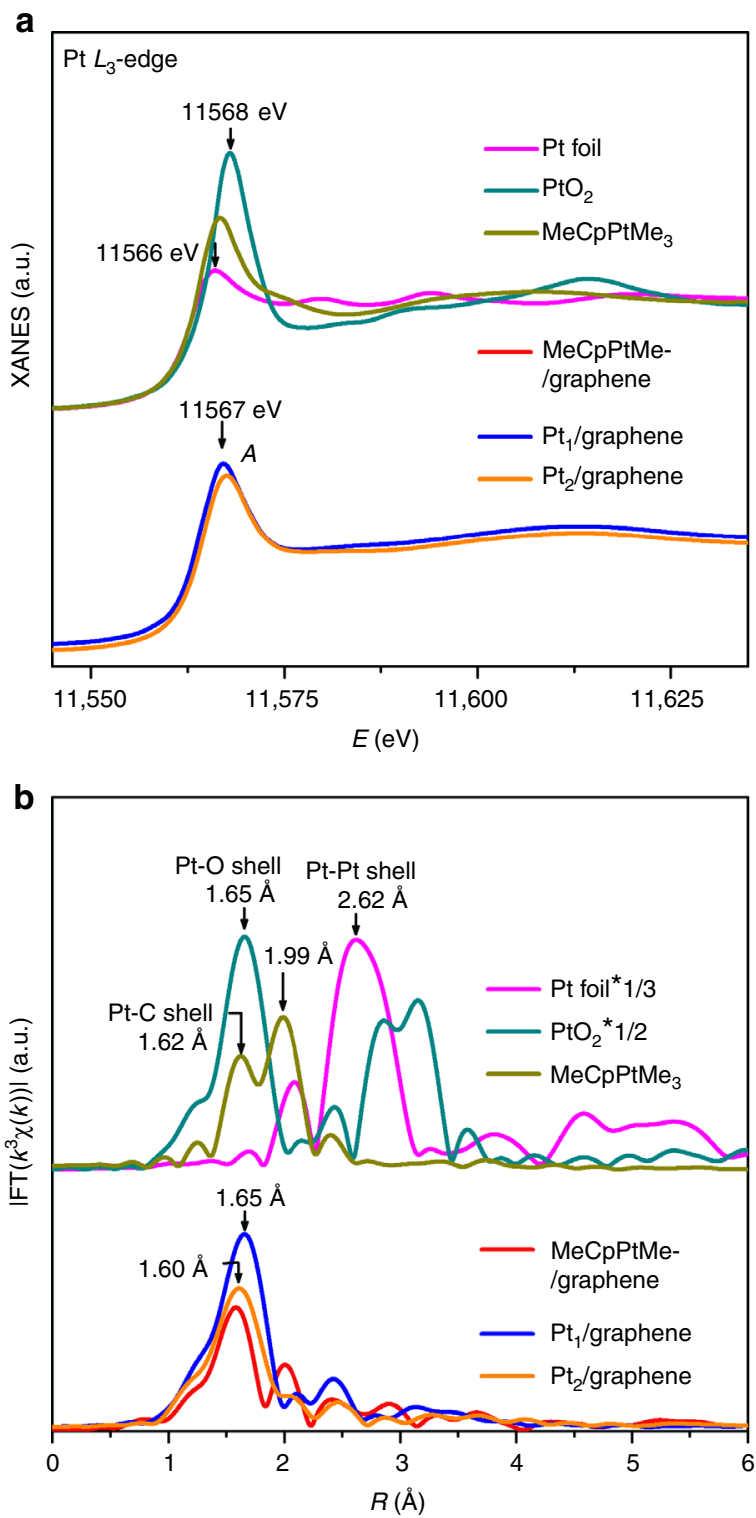
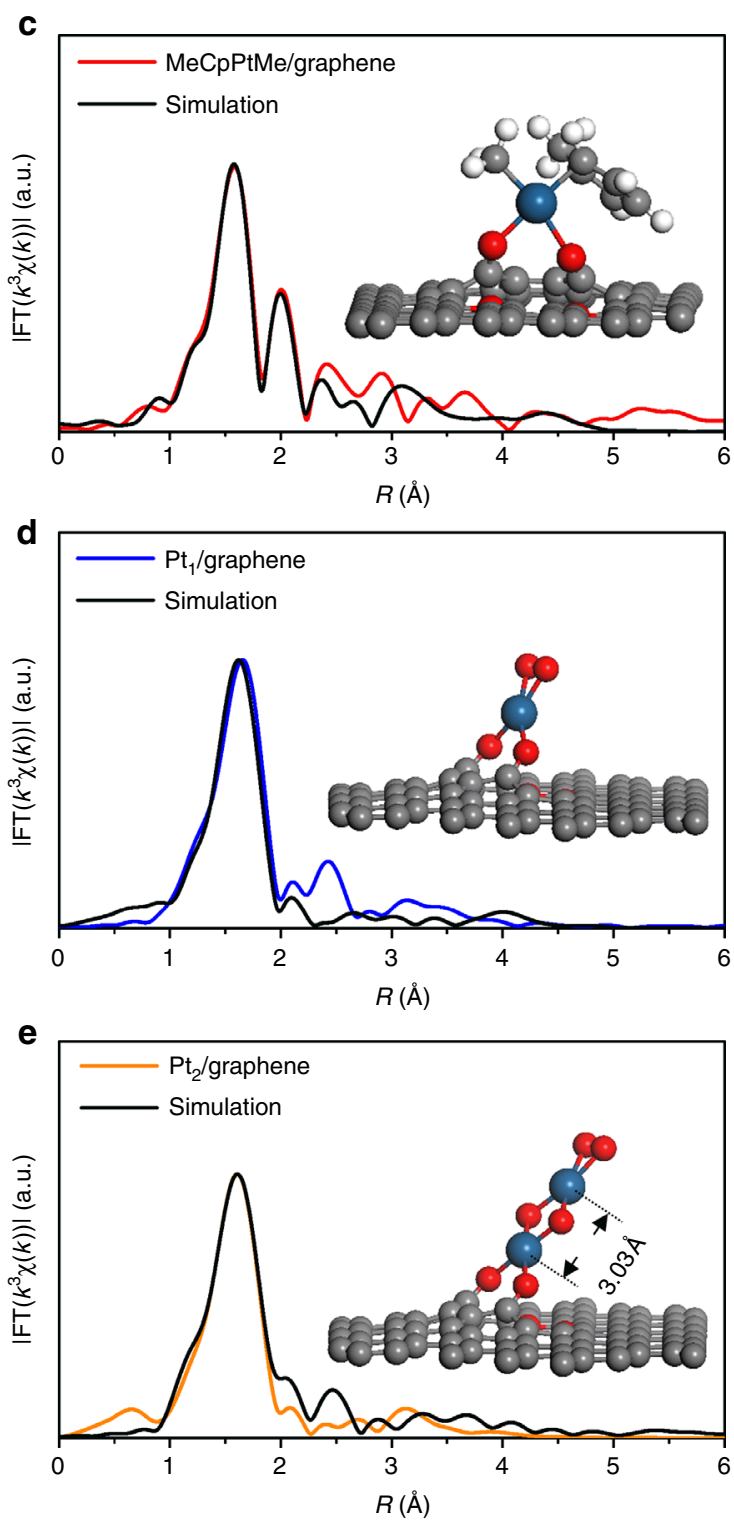

Fig. 3 XAFS structural characterization and spectra simulations. a The XANE spectra and $\mathbf{b}$ the $\mathrm{K}^{2}$-weighted Fourier transform spectra of MeCpPtMe/

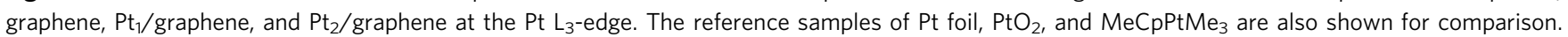
Comparison of the EXAFS simulations based on the corresponding DFT calculated structural models (insets) with the experimental EXAFS spectra of $\mathrm{MeCpPtMe}$ /graphene (c), $\mathrm{Pt}_{1} /$ graphene (d) and $\mathrm{Pt}_{2} /$ graphene (e). The ball in gray, white, red, and dark blue represent carbon, hydrogen, oxygen, and platinum, respectively

the remarkably attenuated peak at $1.99 \AA$ in the MeCpPtMe/ graphene spectrum is due to the considerable distortion of the MeCp group.

When oxygen combusts off the ligand, additional oxygen chemisorbs on the $\mathrm{Pt}_{1}$ atom in the $\mathrm{Pt}_{1} / \mathrm{graphene}$ sample ${ }^{53}$. Indeed, $\mathrm{Pt}_{1}$ atom with one chemisorbed $\mathrm{O}_{2}$ molecule at the terminal position (the $\mathrm{Pt}-\mathrm{O}$ bond distance: $2.00 \AA$ ) and two $\mathrm{O}$ atoms at the interface (the Pt-O bond distance: $2.02 \AA$ ) produces an EXAFS spectrum in good agreement with the experimental result (Fig. 3d and Supplementary Fig. 12). On the contrary, the $\mathrm{Pt}_{1}$ atom with one $\mathrm{O}$ and one $\mathrm{C}$ atom at the interface generates split FT peaks in the first shell, in contrast with the experimental results (Supplementary Fig. 13). Nonetheless, this structure might not be completely ruled out.

During the second Pt ALD cycle, a secondary Pt atom anchors on the preliminary one and then becomes oxidized during the $\mathrm{O}_{3}$ exposure step. Taking this information into account, a $\mathrm{Pt}_{2} \mathrm{O}_{6}$ chain structure with $\mathrm{O}$ atoms alternating between the terminal and bridge positions was constructed (inset in Fig. 3e). After optimization, our calculations show that the Pt-Pt bond distance in the $\mathrm{Pt}_{2} \mathrm{O}_{6}$ chain is $3.03 \AA$ (the inset of Fig. 3e), consistent with the experimental results very well (Fig. $2 \mathrm{~g}$ ). The lengths of the $\mathrm{Pt}-\mathrm{O}$ bonds in the $\mathrm{Pt}_{2} \mathrm{O}_{6}$ chain are very close to each other, 1.93-2.03 A. Moreover, XAFS spectrum simulation for this $\mathrm{Pt}_{2} \mathrm{O}_{6}$ chain structure also agrees very well with the experimental result (Fig. 3e and Supplementary Fig. 12). This chain structure is found to be similar to the suggested structure models for $\mathrm{Pt}_{x} \mathrm{O}_{y}(x$ $=1-3$ ) clusters by Schneider et al. previously ${ }^{54}$. Interestingly, we also noticed that the tilted angle of the $\mathrm{Pt}_{2} \mathrm{O}_{6}$ chain could vary largely from $\sim 8$ to $\sim 50^{\circ}$, depending on both the size of carbon vacancies and the configurations of two interfacial $\mathrm{O}$ atoms (Supplementary Fig. 14). The largely varied angles tilted from the 

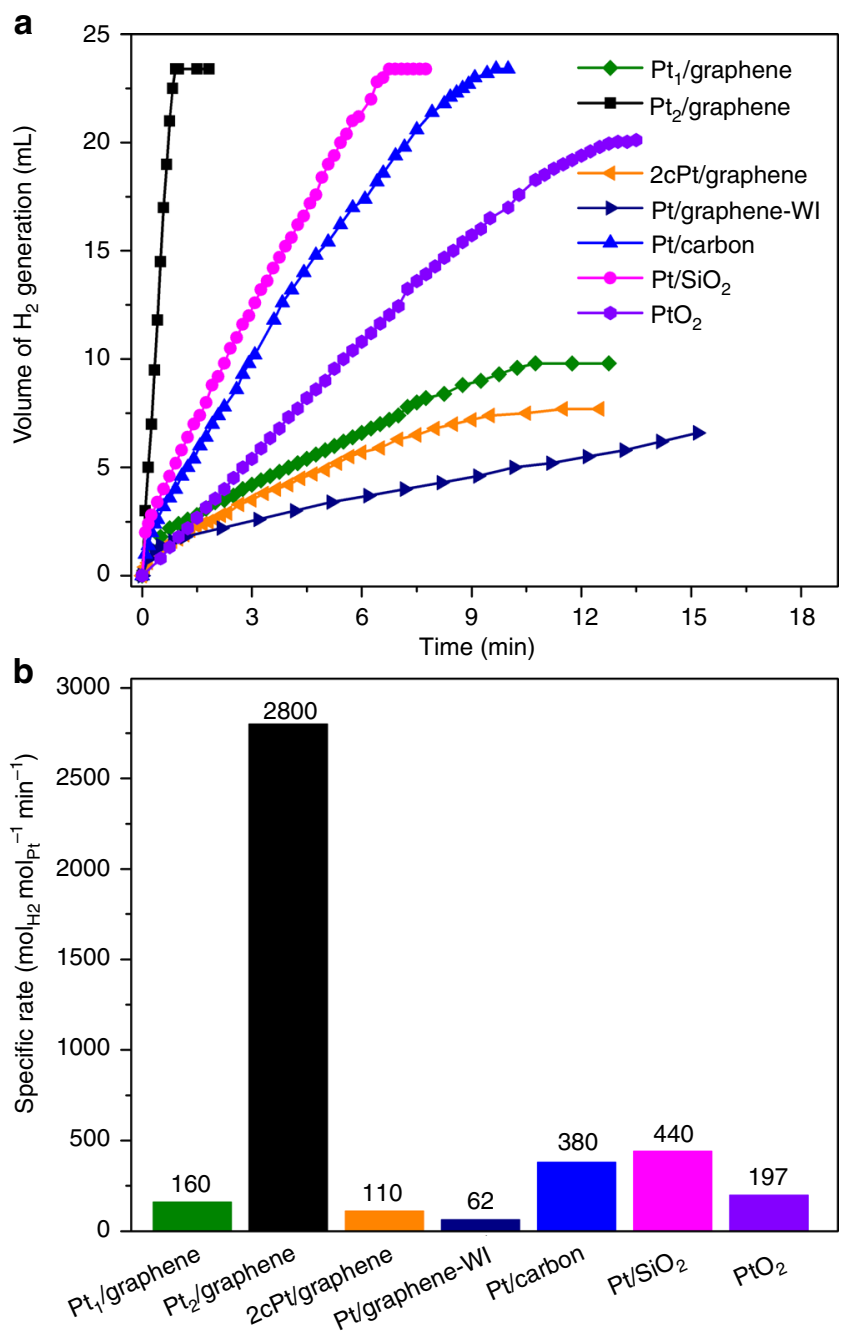

Fig. 4 Catalytic activities of various Pt catalysts in AB hydrolysis. a Plots of time vs normalized volume of hydrogen gas generated from the $A B$ hydrolysis reaction over the single-atom $\mathrm{Pt}_{1} /$ graphene and dimeric $\mathrm{Pt}_{2} /$ graphene catalysts. Pt NPs samples of 2cPt/graphene, Pt/graphene-WI, $\mathrm{Pt} /$ carbon, $\mathrm{Pt} / \mathrm{SiO}_{2}$, and commercial $\mathrm{PtO}_{2}$ powder were also evaluated as a comparison. $\mathbf{b}$ The specific rates over these samples based on the mole of $\mathrm{Pt}$

graphene support, explain well the different $\mathrm{Pt}-\mathrm{Pt}$ bond distances in the $\mathrm{Pt}_{2}$ dimers observed by STEM (Fig. 2e-g). Again, the structure model of $\mathrm{Pt}_{2}$ dimers with one $\mathrm{O}$ and one $\mathrm{C}$ atom at the interface might not be completely ruled out.

Catalytic activity. $\mathrm{AB}$ with satisfactory air stability and remarkably high hydrogen content of $19.6 \mathrm{wt} \%$, has been regarded as a promising hydrogen storage media for portable applications ${ }^{55}$. Here, hydrolysis of $\mathrm{AB}$ for hydrogen production was utilized as a probe reaction to investigate the catalytic properties of $\mathrm{Pt}_{1}$ single atoms and $\mathrm{Pt}_{2}$ dimers. According to literature, this reaction is depicted as the following Eq. (1): ${ }^{56}$

$$
\mathrm{NH}_{3} \mathrm{BH}_{3}+2 \mathrm{H}_{2} \mathrm{O} \rightarrow \mathrm{NH}_{4}^{+}+\mathrm{BO}_{2}^{-}+3 \mathrm{H}_{2}(\mathrm{~g})
$$

As shown in Fig. 4a, the single-atom $\mathrm{Pt}_{1} /$ graphene catalyst generated $9.8 \mathrm{~mL} \mathrm{H}_{2}$ gas only in $10.8 \mathrm{~min}$, which is $\sim 42 \%$ of the theoretical volume of $23.4 \mathrm{~mL}$ according to the Eq. (1). In sharp contrast, the dimeric $\mathrm{Pt}_{2} /$ graphene catalyst released $23.4 \mathrm{~mL}$ $\mathrm{H}_{2}$ vigorously in only $0.9 \mathrm{~min}$, indicating the depletion of $A B$.
The activity of $2 \mathrm{cPt} /$ graphene, synthesized by two successive cycles of $\mathrm{Pt} \mathrm{ALD}$ on graphene at $250{ }^{\circ} \mathrm{C}$, was rather close to $\mathrm{Pt}_{1}$ /graphene, by generating $7.5 \mathrm{~mL} \mathrm{H}_{2}$ in $10.5 \mathrm{~min}$. Obviously, $\mathrm{Pt}_{2}$ /graphene and $2 \mathrm{cPt}$ /graphene were distinctly different in structure. As a comparison, the activities of the Pt NP catalysts of $\mathrm{Pt}$ /graphene-WI, Pt/carbon, and $\mathrm{Pt} / \mathrm{SiO}_{2}$, as well as the commercial $\mathrm{PtO}_{2}$ were tested. The $\mathrm{Pt} /$ graphene-WI catalyst with a Pt particle size of $1.8 \pm 0.5 \mathrm{~nm}$ (Supplementary Fig. 15 and Table 3), showed a very poor activity of $6.6 \mathrm{~mL} \mathrm{H}_{2}$ release in $15.2 \mathrm{~min}$. The commercial Pt/carbon catalyst with a Pt particle size of $2.3 \pm 0.7 \mathrm{~nm}$ (Supplementary Fig. 16 and Table 3) was considerably better, generating $23.4 \mathrm{~mL} \mathrm{H}_{2}$ in $9.7 \mathrm{~min}$. The $\mathrm{Pt} / \mathrm{SiO}_{2}$ ALD catalyst with a $\mathrm{Pt}$ particle size of $1.9 \pm 0.3 \mathrm{~nm}$ (Supplementary Fig. 17 and Table 3) was also very active, releasing $23.4 \mathrm{~mL} \mathrm{H}_{2}$ in $6.8 \mathrm{~min}$. The commercial $\mathrm{PtO}_{2}$ powder (Supplementary Fig. 18) generated $\sim 21 \mathrm{~mL} \mathrm{H}_{2}$ in $15 \mathrm{~min}$. In this case, a reduction of $\mathrm{PtO}_{2}$ into $\mathrm{Pt}$ occurred during the reaction, in line with literature ${ }^{56}$.

The specific rates of these samples were calculated based on the $\mathrm{Pt}$ contents. The rates were 160 and $110 \mathrm{~mol}_{\mathrm{H} 2} \mathrm{Mol}_{\mathrm{Pt}}{ }^{-1} \mathrm{~min}^{-1}$, for $\mathrm{Pt}_{1}$ /graphene and $2 \mathrm{cPt} /$ graphene, respectively (Fig. $4 \mathrm{~b}$ and Supplementary Fig. 19). For the Pt NP samples, the rates were 62, 380, and $440 \mathrm{~mol}_{\mathrm{H} 2} \mathrm{Mol}_{\mathrm{Pt}}{ }^{-1} \mathrm{~min}^{-1}$, for Pt/graphene-WI, Pt/ carbon, and $\mathrm{Pt} / \mathrm{SiO}_{2}$, respectively, close to the values for $\mathrm{Pt}$ catalysts reported in the literature (Supplementary Table 4). The rate of $\mathrm{PtO}_{2}$ was $197 \mathrm{~mol}_{\mathrm{H} 2} \mathrm{Mol}_{\mathrm{Pt}}^{-1} \mathrm{~min}^{-1}$. Obviously, hydrolytic dehydrogenation of $\mathrm{AB}$ on $\mathrm{Pt}$ catalysts is a structure sensitive reaction, the size, and electronic properties of Pt NPs might both play important roles ${ }^{57,58}$. In sharp contrast with the above samples, the $\mathrm{Pt}_{2}$ dimers exhibited the highest rate of $2800 \mathrm{~mol}_{\mathrm{H} 2} \mathrm{Mol}_{\mathrm{Pt}}^{-1} \mathrm{~min}^{-1}$ ever reported in literature, which was $\sim 17$ and 45 times higher than the corresponding singleatom $\mathrm{Pt}_{1} /$ graphene and $\mathrm{Pt} /$ graphene-WI samples, respectively. When the mole ratio of $\mathrm{Pt}$ to the $\mathrm{AB}$ substrate was increased, $\mathrm{Pt}_{2}$ /graphene could preserve the high specific rate to a large extent (Supplementary Fig. 20). Note that all the Pt samples produced a similar product of $\mathrm{BO}_{2}^{-}$in the spent reaction solution, according to the identical ${ }^{11} \mathrm{~B}$ resonance at $8.9 \mathrm{ppm}$ (Supplementary Fig. 21) ${ }^{56}$.

DFT calculations were further carried out to get a deeper insight into the vast activity difference between $\mathrm{Pt}_{1} /$ graphene and $\mathrm{Pt}_{2}$ /graphene. Since $\mathrm{AB}$ is known as an excellent reducing agent ${ }^{59}$, and could likely stripe off the terminal dioxygen of $\mathrm{Pt}_{1}$ /graphene and $\mathrm{Pt}_{2}$ /graphene (the insets of Fig. $3 \mathrm{~d}$, e) during the reaction, partially reduced structures without the terminal dioxygen were considered for both $\mathrm{Pt}_{1} /$ graphene and $\mathrm{Pt}_{2} /$ graphene (the insets of Fig. 5a). The reduced samples are denoted as $\mathrm{Pt}_{1} /$ graphene- $\mathrm{R}$ and $\mathrm{Pt}_{2}$ /graphene- $\mathrm{R}$, respectively. First, we compared the projected density of states of the $5 d$ orbitals of the $\mathrm{Pt}$ atom in $\mathrm{Pt}_{1} /$ graphene$\mathrm{R}$ and the top $\mathrm{Pt}$ atom in $\mathrm{Pt}_{2} /$ graphene- $\mathrm{R}$. It was found that the unoccupied $5 d$ states of the top $\mathrm{Pt}$ atom in $\mathrm{Pt}_{2} /$ graphene- $\mathrm{R}$ locates at a considerably higher energy position of $0.87 \mathrm{eV}$ above Fermi level $\left(E_{\mathrm{f}}\right)$ than that of the $\mathrm{Pt}$ atom in $\mathrm{Pt}_{1} /$ graphene- $\mathrm{R}(0.40 \mathrm{eV})$, which indicates that $\mathrm{Pt}_{1} /$ graphene- $\mathrm{R}$ is more prone to accept electrons than $\mathrm{Pt}_{2} /$ graphene- $\mathrm{R}$ (Fig. 5a). This result is in line with the recent literature where Åstrand et al. reported that $\mathrm{Pt}_{1}$ single atom had a more strong ability to accept electrons than the top $\mathrm{Pt}$ atom in $\mathrm{Pt}_{2}$ dimer, thereby showing stronger $\mathrm{CO}$ adsorption on $\mathrm{Pt}_{1}{ }^{60,61}$.

When $\mathrm{AB}$ is adsorbed on $\mathrm{Pt}_{1}$ /graphene- $\mathrm{R}$, two $\mathrm{B}-\mathrm{H}$ bonds were significantly elongated from 1.22 to $1.42 \AA$, with a strong adsorption energy of $-3.20 \mathrm{eV}$ (Fig. 5b). On $\mathrm{Pt}_{2} /$ graphene- $\mathrm{R}$, the elongation of the two B-H bonds was slightly less, to $1.39 \AA$, and the $\mathrm{AB}$ adsorption energy was considerably weaker, about $-2.81 \mathrm{eV}$ (Fig. 5c). The adsorption of $\mathrm{AB}$ on $\mathrm{Pt}$ (111) was also investigated as a comparison (Supplementary Fig. 22). We found 

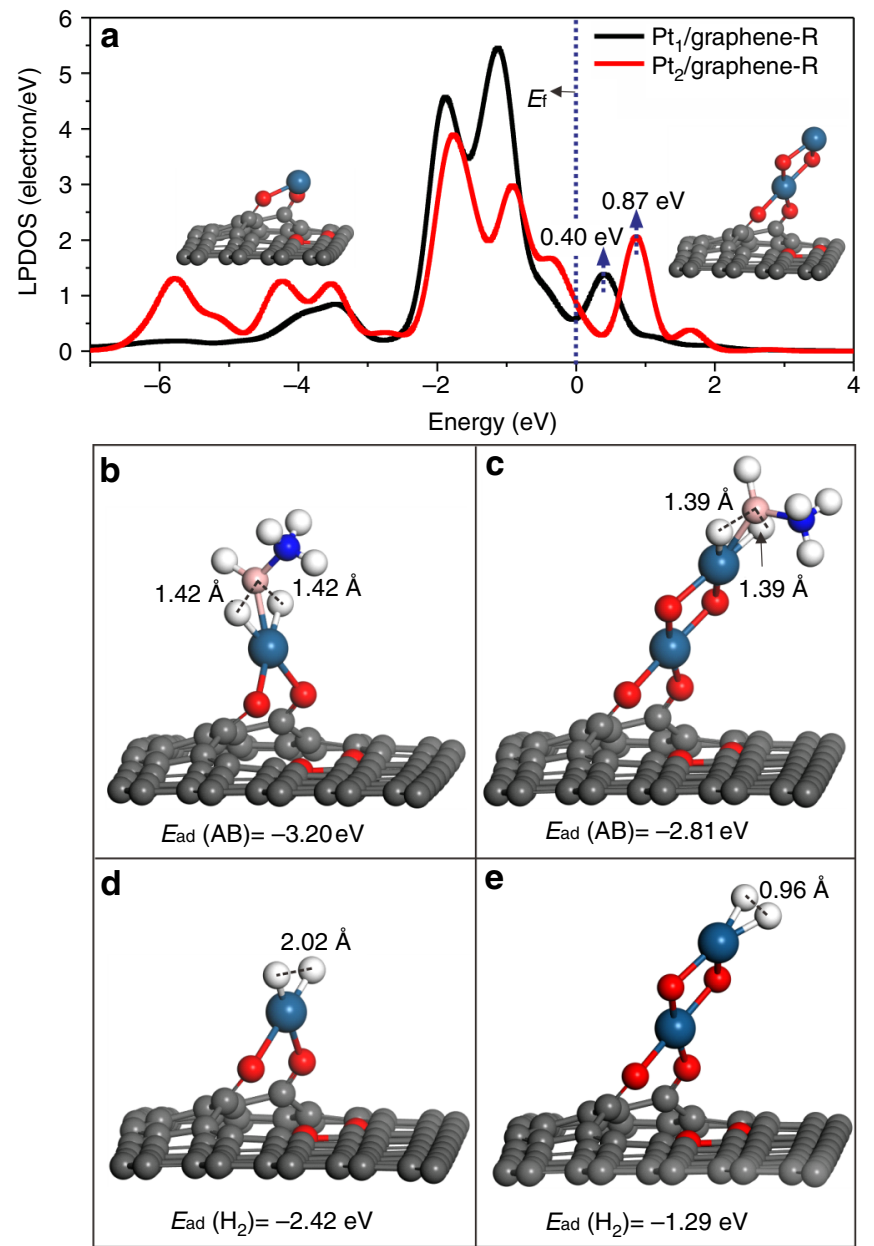

Fig. 5 Electronic properties as well as $A B$ and $\mathrm{H}_{2}$ adsorptions. a The local partial density of state (LPDOS) projected on the Pt $5 d$ orbitals of $\mathrm{Pt}_{1} /$ graphene- $\mathrm{R}$ and the top $\mathrm{Pt}$ atom in $\mathrm{Pt}_{2} /$ graphene- $\mathrm{R}$. The local configurations for $\mathrm{AB}$ adsorption on $\mathrm{Pt}_{1}$ /graphene- $\mathrm{R}$ (b), $\mathrm{Pt}_{2} /$ graphene- $\mathrm{R}$ (c). The local configurations for $\mathrm{H}_{2}$ adsorption on $\mathrm{Pt}_{1} /$ graphene- $\mathrm{R}$ (d), $\mathrm{Pt}_{2} /$ graphene-R (e). The ball in gray, white, pink, blue, red, and dark blue represent carbon, hydrogen, boron, nitrogen, oxygen, and platinum, respectively

that $\mathrm{AB}$ could quickly dissociate to three $\mathrm{H}$ atoms and $\mathrm{BNH}_{3}$ species without any barrier. The $\mathrm{AB}$ adsorption energy is $-3.97 \mathrm{eV}$, significantly stronger than that on $\mathrm{Pt}_{1}$ single atom and $\mathrm{Pt}_{2}$ dimer. The strong $\mathrm{AB}$ adsorption on $\mathrm{Pt}(111)$ revealed by DFT calculations agrees well with the literature ${ }^{57}$, where Pt NP catalyst deactivation induced by $\mathrm{B}$ poisoning was observed during the $\mathrm{AB}$ hydrolysis reaction. Bearing this in mind, we further examined the recycling stabilities of the $\mathrm{Pt}_{1} /$ graphene, $\mathrm{Pt} \mathrm{NP}$, and $\mathrm{PtO}_{2}$ catalysts and measured the $\mathrm{B}$ contents in the used samples using ICP-AES. Indeed, catalyst deactivations and considerable amounts of B adsorption were observed on all the used samples (Supplementary Figs. 23 and 24), in line with the literature ${ }^{57}$. In addition, sintering and leaching of $\mathrm{Pt}$ were also noticed on $\mathrm{Pt}_{1} /$ graphene, $\mathrm{Pt}$ /graphene-WI, and $\mathrm{Pt} / \mathrm{SiO}_{2}$ (Supplementary Fig. 25). Therefore, the considerable weaker adsorption of $\mathrm{AB}$ on $\mathrm{Pt}_{2}$ dimer could be one key factor for its high activity as shown in Fig. 4.

$\mathrm{H}_{2}$ adsorptions on $\mathrm{Pt}_{1} /$ graphene- $\mathrm{R}$ and $\mathrm{Pt}_{2} /$ graphene- $\mathrm{R}$ were also investigated as a descriptor of hydrogen desorption from the catalyst surface during the $\mathrm{AB}$ hydrolysis reaction (Fig. $5 \mathrm{~d}, \mathrm{e}$ ). It was again found that $\mathrm{H}_{2}$ adsorption on $\mathrm{Pt}_{1} /$ graphene- $\mathrm{R}$
$(-2.42 \mathrm{eV})$ is remarkably stronger than that on $\mathrm{Pt}_{2} /$ graphene- $\mathrm{R}$ $(-1.29 \mathrm{eV})$. More interestingly, we found that $\mathrm{H}_{2}$ chemisorbs dissociatively on $\mathrm{Pt}_{1} /$ graphene- $\mathrm{R}$, but molecularly on $\mathrm{Pt}_{2} /$ graphene- $\mathrm{R}$, indicated by the $\mathrm{H}-\mathrm{H}$ bond distance of 2.02 and $0.96 \AA$, respectively. Such molecular adsorption of $\mathrm{H}_{2}$ on the $\mathrm{Pt}_{2}$ dimer with a moderate adsorption energy favors $\mathrm{H}_{2}$ desorption during the $\mathrm{AB}$ hydrolysis reaction, thereby further boosting the catalytic activity. Taken together, compared to $\mathrm{Pt}_{1}$ single atom, the higher energy position of the unoccupied state of the Pt $5 d$ orbital of the top $\mathrm{Pt}$ in the $\mathrm{Pt}_{2}$ dimer might play an important role in weakening the adsorption of both $\mathrm{AB}$ and $\mathrm{H}_{2}$ molecules, thus facilitating the activity remarkably.

Stability of $\mathbf{P t}_{\mathbf{2}}$ dimers on graphene. In sharp contrast with all other Pt samples shown in Supplementary Fig. 23, the dimeric $\mathrm{Pt}_{2}$ /graphene catalyst exhibited a very high stability in the $\mathrm{AB}$ hydrolysis reaction during the recyclability test for five cycles (Fig. 6a). STEM measurements showed that there was no any visible $\mathrm{Pt} \mathrm{NPs}$ formation and $\mathrm{Pt}_{2}$ dimers remained as the main features in the used sample (Fig. 6d, g). The $\mathrm{Pt}_{1}$ single atoms shown in Fig. $6 \mathrm{~g}$ were likely produced by the electron beam during STEM measurements (Supplementary Figs. 7-9), since there was no apparent activity decrease. When $\mathrm{Pt}_{2} /$ graphene was annealed at high temperatures in helium, the activity declined considerably (Fig. 6b), but rates still remained as high as1670 and $1037 \mathrm{~mol}_{\mathrm{H} 2} \mathrm{Mol}_{\mathrm{Pt}}{ }^{-1} \mathrm{~min}^{-1}$ for the sample annealed at $300\left(\mathrm{Pt}_{2} /\right.$ graphene-300C) and $400{ }^{\circ} \mathrm{C}\left(\mathrm{Pt}_{2} /\right.$ graphene-400C), respectively (Fig. 6c). Obviously, significant amounts of $\mathrm{Pt}_{2}$ dimers were survived after the high-temperature treatments. Indeed, HAADFSTEM revealed a mixture of $\mathrm{Pt}_{2}$ dimers, $\mathrm{Pt}_{1}$ single atoms, and $\mathrm{Pt}$ $\mathrm{NPs}$ in both $\mathrm{Pt}_{2} /$ graphene-300C (Fig. 6e, h) and $\mathrm{Pt}_{2} /$ graphene400C (Fig. 6f, i). Please keep in mind that these STEM images might significantly underestimate the portion of $\mathrm{Pt}_{2}$ dimers in the samples owing to the possible beam damage during STEM measurements (Supplementary Figs. 7-9).

In conclusion, we have successfully demonstrated that $\mathrm{Pt}_{2}$ dimers can be bottom-up constructed on graphene with a highsurface area. We found that the type of surface nucleation sites, selective deposition, the self-limiting nature of ALD, and the high stabilities of $\mathrm{Pt}_{1}$ single atoms and $\mathrm{Pt}_{2}$ dimers are the keys factors for the $\mathrm{Pt}_{2}$ dimers synthesis. The dominant presence of $\mathrm{Pt}_{2}$ dimers on graphene in the oxidized form of $\mathrm{Pt}_{2} \mathrm{O}_{x}$ were confirmed by a combination of aberration-corrected HAADF-STEM, ICP-AES, and XAFS and DFT calculations. Rotating and uncoupling of $\mathrm{Pt}_{2}$ dimers under the electron beam during STEM measurements, provide direct evidence of the presence of $\mathrm{Pt}_{2}$ dimers on graphene. In the $\mathrm{AB}$ hydrolysis reaction, the dimeric $\mathrm{Pt}_{2} /$ graphene catalyst exhibited a strikingly high activity, which was 17- and 45-fold higher than graphene supported $\mathrm{Pt}_{1}$ single atoms and Pt NPs, respectively. The lower adsorption energies of $\mathrm{AB}$ and $\mathrm{H}_{2}$ on the $\mathrm{Pt}_{2}$ dimers than that on $\mathrm{Pt}_{1}$ single atoms or $\mathrm{Pt}$ NPs are likely the major reasons for the high activity. Importantly, the dimeric $\mathrm{Pt}_{2}$ /graphene catalyst showed a high stability under the current reaction conditions and in the inert environment at below $300^{\circ} \mathrm{C}$. Finally, our findings point out a new avenue to bottom-up synthesis of atomically precise ultrafine metal (and/or metal oxide) clusters on high-surface area supports for advanced catalysis.

\section{Methods}

Materials. Trimethyl(methylcyclopentadienyl)platinum(IV) ( $\mathrm{MeCpPtMe}_{3}, 98 \%$ ), chloroplatinic acid $\left(\mathrm{H}_{2} \mathrm{PtCl}_{6}, \geq 99.9 \%\right.$, trace metals basis), ammonia borane (97\%), the commercial $\mathrm{PtO}_{2}\left(\geq 99.9 \%, 70 \mathrm{~m}^{2} / \mathrm{g}\right)$, and $\mathrm{Pt} /$ carbon catalysts (the Pt content, $5.0 \mathrm{wt} \%)$ were all purchased from Sigma Aldrich. Silica gel was purchased from Alfa Aesar (Brunauer, Emmett, and Teller (BET) surface area $300 \mathrm{~m}^{2} / \mathrm{g}$ ). Pristine graphene nanosheet $(99.5 \%)$ was bought from Chengdu Organic Chemicals Co. 

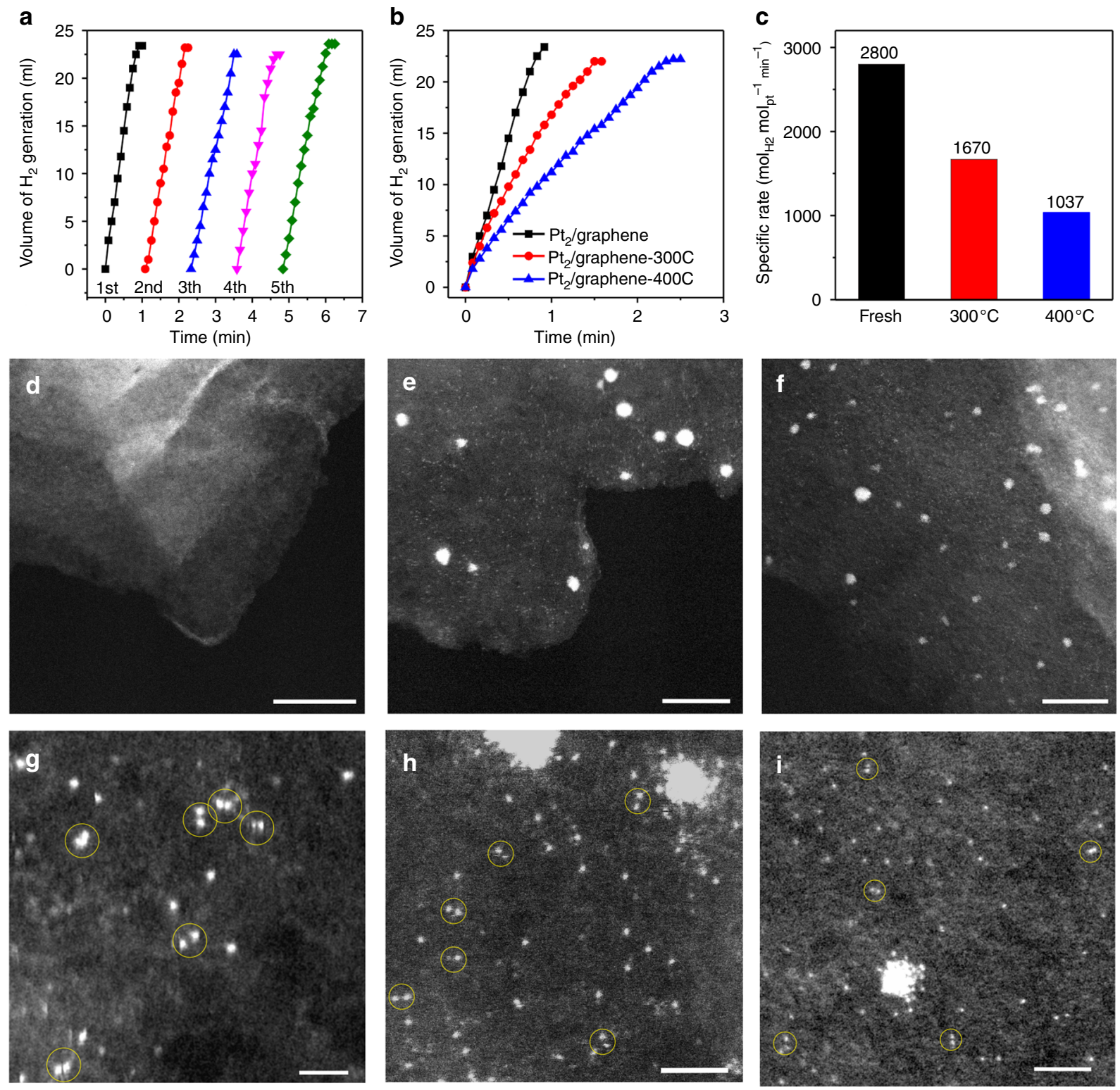

Fig. 6 Stability of the dimeric $\mathrm{Pt}_{2} /$ graphene catalyst. a Five recycles in hydrolytic dehydrogenation of $\mathrm{AB}$ at room temperature over the dimeric $\mathrm{Pt} / 2$ graphene catalyst by adding additional $0.325 \mathrm{mmol}$ of pure $A B$ into the reaction flask after each run. $\mathbf{b}$ Plots of time vs volume of hydrogen gas generated from $A B$ hydrolysis and $\mathbf{c}$ the corresponding specific rates at room temperature over the dimeric $\mathrm{Pt}_{2} / \mathrm{graphene}$ catalysts after different pretreatments: asprepared, annealing in helium at 300 and $400^{\circ} \mathrm{C}$ for $1 \mathrm{~h}$, respectively. d, $\mathbf{g}$ Representative HAADF-STEM images of the used Pt $/$ graphene catalyst after the recyclability test, scale bars, $20 \mathrm{~nm}(\mathbf{d}), 1 \mathrm{~nm}(\mathbf{g})$. e, h Representative HAADF-STEM images of the $\mathrm{Pt}_{2} / \mathrm{graphene}$ catalyst after annealing in helium at $300^{\circ} \mathrm{C}$ for $1 \mathrm{~h}$, scale bars, $10 \mathrm{~nm}(\mathbf{e}), 2 \mathrm{~nm}(\mathbf{h}) . \mathbf{f}$, i Representative HAADF-STEM images of the $\mathrm{Pt}_{2} /$ graphene catalyst after annealing in helium at $400{ }^{\circ} \mathrm{C}$ for $1 \mathrm{~h}$, scale bars, $10 \mathrm{~nm}(\mathbf{f}), 2 \mathrm{~nm}$ (i). $\mathrm{Pt}_{2}$ dimers in $\mathbf{g}$-i are highlighted by yellow circles

Ltd., Chinese Academy of Sciences. All materials were used as received without further purification.

Preparation of reduced graphene oxide. Pristine graphene nanosheet was first oxidized to graphene oxide according to the procedure described previously ${ }^{62}$. In brief, $0.6 \mathrm{~g}$ graphene nanosheet and $0.3 \mathrm{~g}$ sodium nitrate was sequentially added into concentrated sulfuric acid $\left(\mathrm{H}_{2} \mathrm{SO}_{4}, 15 \mathrm{~mL}\right)$ and stirred at room temperature for $22 \mathrm{~h}$. Then the mixture was cooled down to $0^{\circ} \mathrm{C}$ to add $1.8 \mathrm{~g}$ potassium permanganate $\left(\mathrm{KMnO}_{4}\right)$. After stirring at room temperature and $35^{\circ} \mathrm{C}$ for 2 and $3 \mathrm{~h}$, respectively, the mixture was heated to $98^{\circ} \mathrm{C}$ and kept at this temperature for another $30 \mathrm{~min}$. Next, it was cooled down to $40^{\circ} \mathrm{C}$, and $90 \mathrm{~mL}$ of water and $7.5 \mathrm{~mL}$ of hydrogen peroxide $\left(\mathrm{H}_{2} \mathrm{O}_{2}, 30 \%\right)$ were slowly added into the mixture. After that the precipitate was filtered out by washing with $\mathrm{HCl}(5 \%)$ and ultrapure water, it was dried in a vacuum oven at $45^{\circ} \mathrm{C}$ overnight. The dry material was grinded to obtain graphene oxide powder. Finally, the reduced graphene oxide was obtained by thermal deoxygenation of graphene oxide powder at $1050{ }^{\circ} \mathrm{C}$ for $2 \mathrm{~min}$ under helium at a flow rate of $50 \mathrm{~mL} / \mathrm{min}$.
Synthesis of $\mathbf{P t}_{1} / \mathbf{g r a p h e n e}$. Pt ALD was carried out on a viscous flow reactor (GEMSTAR-6 Benchtop ALD, Arradiance) by alternatively exposing to $\mathrm{MeCpPtMe}_{3}$ precursor and $\mathrm{O}_{2}(99.999 \%)$ at $250^{\circ} \mathrm{C}^{46,63,64}$. Ultrahigh purity $\mathrm{N}_{2}$ (99.999\%) was used as the carrier gas at a flow rate of $200 \mathrm{~mL} / \mathrm{min}$. The Pt precursor was heated to $65^{\circ} \mathrm{C}$ to get a sufficient vapor pressure. The reactor inlets were held at $110^{\circ} \mathrm{C}$ to avoid any precursor condensation. The timing sequence was 90 , 120,60 , and $120 \mathrm{sec}$ for the $\mathrm{MeCpPtMe}_{3}$ exposure, $\mathrm{N}_{2}$ purge, $\mathrm{O}_{2}$ exposure, and $\mathrm{N}_{2}$ purge, respectively (90-120-60-120).

Synthesis of $\mathbf{P t}_{\mathbf{2}} / \mathbf{g r a p h e n e . ~ T h e ~ s e c o n d ~ P t ~ A L D ~ c y c l e ~ w a s ~ p e r f o r m e d ~ o n ~ t h e ~} \mathrm{Pt}_{1} /$ graphene $\mathrm{SAC}$ at $150^{\circ} \mathrm{C}$. Here, $\mathrm{O}_{3}$ was used as the oxidant to make sure that the precursor ligand can be fully removed ${ }^{65}$. The timing sequence was 90-120-60-120.

Synthesis of 2cPt/graphene. Two consecutive cycles of Pt ALD was also performed on the reduced graphene oxide at $250^{\circ} \mathrm{C}$ using the same timing sequence. 
Synthesis of $\mathbf{P t} / \mathrm{SiO}_{2}$. Pt ALD was performed on the silica gel support for one cycle at $250^{\circ} \mathrm{C}$ using the same timing sequence.

Synthesis of Pt/graphene-WI. A Pt/graphene NP catalyst was synthesized by the wetness impregnation method (Pt/graphene-WI). In this case, $100 \mathrm{mg}$ graphene support was slowly added into a $1.93 \times 10^{-2} \mathrm{M} \mathrm{H}_{2} \mathrm{PtCl}_{6}$ aqueous solution $(0.9 \mathrm{~mL})$. Then, the mixture was stirred for $30 \mathrm{~min}$, and then dried in air at room temperature for $12 \mathrm{~h}$. The dried material was first calcined in air at $120^{\circ} \mathrm{C}$ for $12 \mathrm{~h}$, and then reduced in $10 \% \mathrm{H}_{2}$ in argon at $300{ }^{\circ} \mathrm{C}$ for another $2 \mathrm{~h}$ to get the $\mathrm{Pt} /$ grapheneWI catalyst.

Catalyst characterization. The Pt loadings in these samples were determined by ICP-AES measurements; therein all samples were dissolved in hot fresh aqua regia. The BET surface area was measured on a Micromeritics ASAP 2020 system. Raman spectra were recorded on a LabRAM HR Raman spectrometer with a $514 \mathrm{~nm} \mathrm{Ar}$ laser in backscattering geometry. Aberration-corrected HAADF-STEM measurements were taken on a JEM-ARM200F instrument (University of Science and Technology of China) at $200 \mathrm{keV}$. XAFS measurements at the Pt $L_{3}$-edge $(11,564 \mathrm{eV})$ were performed in the transmission mode with the Si (111) monochromator at the BL14W1 beamline of the Shanghai Synchrotron Radiation Facility (SSRF), China. The storage ring of SSRF worked at $3.5 \mathrm{GeV}$ with a maximum current of $210 \mathrm{~mA}$.

XAFS data analysis and simulation. The acquired EXAFS data were processed according to the standard procedures using the ATHENA module implemented in the IFEFFIT software packages ${ }^{61}$.The EXAFS oscillation functions $\chi(k)$ were obtained by subtracting the post-edge background from the overall absorption spectra and then normalized with respect to the edge-jump step. The $R_{\mathrm{bkg}}$ value of 1.0 was used for all samples. Subsequently, $k^{3}$-weighted $\chi(k)$ fucntions in the $k$ range of $2.2-13.5 \AA^{-1}$ were FT to the $R$ space by using a Hanning window of $d k=$ $3.0 \AA^{-1}$

EXAFS simulations were performed with the FEFF8.4 code $^{62}$ using the structural models suggested by DFT calculations. The simulated EXAFS $\chi(k)$ functions were also $k^{3}$-weighted and FT into the $R$-space by using the same $k$ range of $2.2-13.5 \AA^{-1}$ as that in the experimental data. During simulations, the coordination numbers were set to the values of the model structures generated by DFT calculations. The amplitude reduction factor $S_{0}{ }^{2}$ was fixed at the value of 0.86 which was determined by fitting the reference metal Pt foil. The Debye-Waller factors for the nearest $\mathrm{Pt}-\mathrm{O} / \mathrm{C}$ and $\mathrm{Pt}-\mathrm{Pt}$ pairs were set at the typical values of 0.0030 and $0.0065 \AA^{2}$ determined from the fittings of $\mathrm{PtO}_{2}$ and Pt foil references, respectively, and they were set at $0.008 \AA^{2}$ for all the other distant paths which contributed barely discernible signals as seen from the experimental data in the $R$-space. To further improve the match between the simulation and the experimental data, for the $\mathrm{MeCpPtMe/graphene} \mathrm{sample,} \mathrm{the}$ two nearest Pt-C and Pt-O interatomic distances were optimized to 2.00 and $2.02 \AA$, respectively, both of which are within $\sim 2 \%$ error level as compared to the optimized structure by DFT calculations ( 2.05 and $2.06 \AA$, respectively). For the other two samples, the simulated EXAFS spectra based on the DFTgenerated structures match well with the experimental data, thus no further structure optimization was performed during EXAFS simulations.

DFT Calculations. All spin-polarized calculations were performed by using the DFT method. The DFT Semi-core Pseudopotential method ${ }^{66}$ with a double numerical basis set together with polarization functions (DNP) were adopted to form the Perdew-Burke-Ernzerhof (PBE) exchange-correlation functional within the generalized gradient approximation ${ }^{67}$, implemented in $\mathrm{DMol}^{3}$ package $\left(\mathrm{DMol}^{3}\right.$ is a density functional theory quantum mechanical package available from Accelrys Software Inc. $)^{68}$. A DFT-D semi-empirical correction with Tkatchenko-Scheffler (TS) method is applied with the PBE functional to account for the dispersion interaction. Conductor-like screening model (COSMO) with a dielectric constant of 78.54 is adopted to consider the water solvent effect regarding the adsorption of molecule and fragment in $\mathrm{AB}$ hydrolysis. A smearing of $0.001 \mathrm{Ha}$ to the orbital occupation is applied to achieve electronic convergence. The real-space global cutoff radius is set to be $4.5 \AA$. A hexagonal supercell containing $(8 \times 8)$ unit cells of graphene monolayer with about $17 \AA$ vacuum layer was used as a support. The convergence tolerances of energy, force, and displacement for the geometry optimization were $1 \times 10^{-5} \mathrm{Ha}, 0.002 \mathrm{Ha} / \AA$, and $0.005 \AA$, respectively. $1 \times 1 \times 1 \mathrm{k}$ points grid is used to describe the Brillouin zone for geometric optimization. The adsorption energy is defined by the formula: $E_{\mathrm{ads}(\mathrm{AB})}=E_{(\mathrm{AB} / \text { catalyst })}-\left(E_{\text {catalyst }}+\right.$ $\left.E_{\mathrm{AB}}\right)$ and $E_{\mathrm{ads}(\mathrm{H} 2)}=E_{(\mathrm{H} 2 / \text { catalyst })}-\left(E_{\text {catalyst }}+E_{\mathrm{H} 2 \text {,gas }}\right)$, where $E_{(\mathrm{AB} / \text { catalyst })}, E_{(\mathrm{H} 2 / \text { catalyst })}$, and $E_{\text {catalyst }}$ are the total energies for the optimized equilibrium configurations of catalyst with and without $\mathrm{AB}$ or $\mathrm{H}_{2}$, respectively; and $E_{\mathrm{AB}}\left(E_{\mathrm{H} 2, \text { gas }}\right)$ is the energy of the $\mathrm{AB}$ (gas phase $\mathrm{H}_{2}$ ) molecule in its ground state. For $\mathrm{Pt}(111)$, the supercell is $(4 \times 4)$.

Hydrolytic dehydrogenation of $\mathbf{A B}$. As a probe reaction, hydrolytic dehydrogenation of $\mathrm{AB}$ was performed in a three-necked flask at $27^{\circ} \mathrm{C}$ under atmospheric pressure. The flask was immersed in a water bath to control the reaction temperature. $10 \mathrm{mg}$ of the $\mathrm{Pt}_{2} /$ graphene catalyst was used, while the weight of other catalysts was adjusted to keep the same amount of $\mathrm{Pt}$ with $\mathrm{Pt}_{2} /$ graphene. Typically, $5 \mathrm{~mL}$ aqueous $\mathrm{AB}$ solution $\left(6.5 \times 10^{-2} \mathrm{M}\right)$ were introduced into the glass container via a syringe. For the commercial $\mathrm{PtO}_{2}$ catalyst, the mole ratio of $\mathrm{Pt}$ to $\mathrm{AB}$ was kept as the same with other samples, and the result was normalized to other samples based the amount of Pt. The AB solution and the catalyst were well-mixed by using a magnetic stirrer at a speed of $800 \mathrm{r} / \mathrm{min}$ to eliminate any mass-transfer issue. The generated volume of $\mathrm{H}_{2}$ was measured by a water-filled gas burette, where the volume of water discharged was converted into the volume of hydrogen generated $^{69}$

The specific rates $(r)$ of these catalysts were calculated according to the Eq. (2):

$$
r=\frac{n_{\mathrm{H} 2}}{n_{\mathrm{Pt}} \times t}
$$

Here $n_{\mathrm{H} 2}$ is the mole of generated $\mathrm{H}_{2}$, while $n_{\mathrm{Pt}}$ is the total mole of Pt in the sample. $t$ is the reaction time in min.

Data availability. All the relevant data are available from the authors upon request.

Received: 21 February 2017 Accepted: 4 September 2017

Published online: 20 October 2017

\section{References}

1. Bartholomew, C. H. \& Farrauto, R. J. Fundamentals of Industrial Catalytic Processes. 2nd edn, (Wiley, 2006).

2. Funabiki, M., Yamada, T. \& Kayano, K. Auto exhaust catalysts. Catal. Today 10, 33-43 (1991)

3. Guo, Z. et al. Recent advances in heterogeneous selective oxidation catalysis for sustainable chemistry. Chem. Soc. Rev. 43, 3480-3524 (2014).

4. Shanks, B. H. Conversion of biorenewable feedstocks: new challenges in heterogeneous catalysis. Ind. Eng. Chem. Res. 49, 10212-10217 (2010).

5. Khodakov, A. Y., Chu, W. \& Fongarland, P. Advances in the development of novel cobalt Fischer-Tropsch catalysts for synthesis of long-chain hydrocarbons and clean fuels. Chem. Rev. 107, 1692-1744 (2007).

6. Alonso, D. M., Wettstein, S. G. \& Dumesic, J. A. Bimetallic catalysts for upgrading of biomass to fuels and chemicals. Chem. Soc. Rev. 41, 8075-8098 (2012).

7. Calle-Vallejo, F., Koper, M. T. M. \& Bandarenka, A. S. Tailoring the catalytic activity of electrodes with monolayer amounts of foreign metals. Chem. Soc. Rev. 42, 5210-5230 (2013)

8. Kaden, W. E., Wu, T. P., Kunkel, W. A. \& Anderson, S. L. Electronic structure controls reactivity of size-selected Pd clusters adsorbed on $\mathrm{TiO}_{2}$ surfaces. Science 326, 826-829 (2009).

9. Palmer, R. E., Pratontep, S. \& Boyen, H. G. Nanostructured surfaces from sizeselected clusters. Nat. Mater. 2, 443-448 (2003).

10. Li, Z. Y. et al. Three-dimensional atomic-scale structure of size-selected gold nanoclusters. Nature 451, 46-48 (2008).

11. Abbet, S. et al. Acetylene cyclotrimerization on supported size-selected Pd-n clusters $(1<=\mathrm{n}<=30)$ : one atom is enough. J. Am. Chem. Soc. 122, 3453-3457 (2000).

12. Yoon, B. et al. Charging effects on bonding and catalyzed oxidation of $\mathrm{CO}$ on Au-8 clusters on MgO. Science 307, 403-407 (2005).

13. Nesselberger, M. et al. The effect of particle proximity on the oxygen reduction rate of size-selected platinum clusters. Nat. Mater. 12, 919-924 (2013).

14. Vajda, S. et al. Subnanometre platinum clusters as highly active and selective catalysts for the oxidative dehydrogenation of propane. Nat. Mater. 8, 213-216 (2009).

15. Yang, X. F. et al. Single-atom catalysts: a new frontier in heterogeneous catalysis. Acc. Chem. Res. 46, 1740-1748 (2013).

16. Yang, $\mathrm{M}$. et al. Catalytically active $\mathrm{Au}-\mathrm{O}(\mathrm{OH})(\mathrm{x})$-species stabilized by alkali ions on zeolites and mesoporous oxides. Science 346, 1498-1501 (2014).

17. Flytzani-Stephanopoulos, M. Gold atoms stabilized on various supports catalyze the water-gas shift reaction. Acc. Chem. Res. 47, 783-792 (2014).

18. Qiao, B. T. et al. Single-atom catalysis of CO oxidation using Pt-1/FeOx. Nat. Chem. 3, 634-641 (2011).

19. Peterson, E. J. et al. Low-temperature carbon monoxide oxidation catalysed by regenerable atomically dispersed palladium on alumina. Nat. Commun. 5, 4885 (2014).

20. Vile, G. et al. A stable single-site palladium catalyst for hydrogenations. Angew. Chem. Int. Ed. 54, 11265-11269 (2015).

21. Liu, P. X. et al. Photochemical route for synthesizing atomically dispersed palladium catalysts. Science 352, 797-801 (2016).

22. Yan, H. et al. Single-atom pd-1/graphene catalyst achieved by atomic layer deposition: remarkable performance in selective hydrogenation of 1,3butadiene. J. Am. Chem. Soc. 137, 10484-10487 (2015). 
23. Ding, K. et al. Identification of active sites in $\mathrm{CO}$ oxidation and water-gas shift over supported Pt catalysts. Science 350, 189-192 (2015).

24. Jin, R. C., Zeng, C. J., Zhou, M. \& Chen, Y. X. Atomically precise colloidal metal nanoclusters and nanoparticles: fundamentals and opportunities. Chem. Rev. 116, 10346-10413 (2016).

25. Yoskamtorn, T. et al. Thiolate-mediated selectivity control in aerobic alcohol oxidation by porous carbon-supported Au- 25 clusters. ACS Catal. 4, 3696-3700 (2014).

26. Fang, J. et al. The support effect on the size and catalytic activity of thiolated Au-25 nanoclusters as precatalysts. Nanoscale 7, 6325-6333 (2015).

27. Das, S. et al. Reductive deprotection of monolayer protected nanoclusters: an efficient route to supported ultrasmall au nanocatalysts for selective oxidation. Small 10, 1473-1478 (2014)

28. Liu, J. et al. Ligand-stabilized and atomically precise gold nanocluster catalysis: a case study for correlating fundamental electronic properties with catalysis. Chem. Eur. J. 19, 10201-10208 (2013).

29. Nie, X. T., Qian, H. F., Ge, Q. J., Xu, H. Y. \& Jin, R. C. CO oxidation catalyzed by oxide-supported $\mathrm{Au}-25(\mathrm{SR})(18)$ nanoclusters and identification of perimeter sites as active centers. ACS Nano 6, 6014-6022 (2012).

30. $\mathrm{Wu}, \mathrm{Z}$. L. et al. Thiolate ligands as a double-edged sword for $\mathrm{CO}$ oxidation on $\mathrm{CeO} 2$ Supported $\mathrm{Au}-25(\mathrm{SCH} 2 \mathrm{CH} 2 \mathrm{Ph})(18)$ Nanoclusters. J. Am. Chem. Soc. 136, 6111-6122 (2014).

31. Xu, Z. et al. Size-dependent catalytic activity of supported metal-clusters. Nature 372, 346-348 (1994).

32. Argo, A. M., Odzak, J. F., Lai, F. S. \& Gates, B. C. Observation of ligand effects during alkene hydrogenation catalysed by supported metal clusters. Nature 415, 623-626 (2002).

33. Gates, B. C. Supported metal-clusters - synthesis, structure, and catalysis. Chem. Rev. 95, 511-522 (1995)

34. George, S. M. Atomic layer deposition: an overview. Chem. Rev. 110, 111-131 (2010).

35. Puurunen, R. L. Surface chemistry of atomic layer deposition: a case study for the trimethylaluminum/water process. J. Appl. Phys. 97, 121301 (2005).

36. Knez, M., Niesch, K. \& Niinisto, L. Synthesis and surface engineering of complex nanostructures by atomic layer deposition. Adv. Mater. 19, 3425-3438 (2007).

37. Lu, J. L., Elam, J. W. \& Stair, P. C. Atomic layer deposition-Sequential selflimiting surface reactions for advanced catalyst "bottom-up" synthesis. Surf. Sci. Rep. 71, 410-472 (2016).

38. O'Neill, B. J. et al. Catalyst design with atomic layer deposition. ACS Catal. 5, 1804-1825 (2015).

39. Detavernier, C., Dendooven, J., Sree, S. P., Ludwig, K. F. \& Martens, J. A. Tailoring nanoporous materials by atomic layer deposition. Chem. Soc. Rev. 40, 5242-5253 (2011)

40. Bagri, A. et al. Structural evolution during the reduction of chemically derived graphene oxide. Nat. Chem. 2, 581-587 (2010).

41. Kim, K. et al. Selective metal deposition at graphene line defects by atomic layer deposition. Nat. Commun. 5, 4781 (2014)

42. Lu, J. L. et al. Toward atomically-precise synthesis of supported bimetallic nanoparticles using atomic layer deposition. Nat. Commun. 5, 3264 (2014).

43. Kessels, W. M. M., Knoops, H. C. M., Dielissen, S. A. F., Mackus, A. J. M. \& van de Sanden, M. C. M. Surface reactions during atomic layer deposition of Pt derived from gas phase infrared spectroscopy. Appl. Phys. Lett. 95, 013114 (2009).

44. Aaltonen, T., Rahtu, A., Ritala, M. \& Leskela, M. Reaction mechanism studies on atomic layer deposition of ruthenium and platinum. Electrochem. Solid State Lett. 6, C130-C133 (2003).

45. Mackus, A. J. M., Leick, N., Baker, L. \& Kessels, W. M. M. Catalytic combustion and dehydrogenation reactions during atomic layer deposition of platinum. Chem. Mater. 24, 1752-1761 (2012).

46. Hamalainen, J., Ritala, M. \& Leskela, M. Atomic layer deposition of noble metals and their oxides. Chem. Mater. 26, 786-801 (2014).

47. Xue, Z. L. et al. Characterization of (Methylcyclopentadienyl)trimethylplatinum and low-temperature organometallic chemical vapor-deposition of platinum metal. J. Am. Chem. Soc. 111, 8779-8784 (1989).

48. Gong, T. et al. Activated carbon supported palladium nanoparticle catalysts synthesized by atomic layer deposition: genesis and evolution of nanoparticles and tuning the particle size. J. Phys. Chem. C 119, 11544-11556 (2015).

49. Lacroix, L. M., Arenal, R. \& Viau, G. Dynamic HAADF-STEM observation of a single-atom chain as the transient state of gold ultrathin nanowire breakdown. J. Am. Chem. Soc. 136, 13075-13077 (2014).

50. Shen, J., Muthukumar, K., Jeschke, H. O. \& Valenti, R. Physisorption of an organometallic platinum complex on silica: an ab initio study. New J. Phys. 14 (2012).
51. Setthapun, W. et al. Genesis and evolution of surface species during pt atomic layer deposition on oxide supports characterized by in situ xafs analysis and water-gas shift reaction. J. Phys. Chem. C 114, 9758-9771 (2010).

52. Karasulu, B., Vervuurt, R. H. J., Kessels, W. M. M. \& Bo, A. A. Continuous and ultrathin platinum films on graphene using atomic layer deposition: a combined computational and experimental study. Nanoscale 8, 19829 (2016).

53. Moses-DeBusk, M. et al. CO oxidation on supported single pt atoms: experimental and $\mathrm{ab}$ initio density functional studies of co interaction with $\mathrm{Pt}$ Atom on theta-Al2O3(010) surface. J. Am. Chem. Soc. 135, 12634-12645 (2013).

54. Xu, Y., Shelton, W. A. \& Schneider, W. F. Thermodynamic equilibrium compositions, structures, and reaction energies of PtxOy $(x=1-3)$ clusters predicted from first principles. J. Phys. Chem. B 110, 16591-16599 (2006).

55. Hamilton, C. W., Baker, R. T., Staubitz, A. \& Manners, I. B-N compounds for chemical hydrogen storage. Chem. Soc. Rev. 38, 279-293 (2009).

56. Chandra, M. \& Xu, Q. A high-performance hydrogen generation system: Transition metal-catalyzed dissociation and hydrolysis of ammonia-borane. J. Power Sources 156, 190-194 (2006).

57. Chen, W. Y. et al. Mechanistic insight into size-dependent activity and durability in $\mathrm{pt} / \mathrm{cnt}$ catalyzed hydrolytic dehydrogenation of ammonia borane. J. Am. Chem. Soc. 136, 16736-16739 (2014).

58. Chen, W. Y. et al. Unique reactivity in Pt/CNT catalyzed hydrolytic dehydrogenation of ammonia borane. Chem. Commun. 50, 2142-2144 (2014)

59. Andrews, G. C. \& Crawford, T. C. Synthetic utility of amine borane reagents in the reduction of aldehydes and ketones. Tetrahedron Lett. 21, 693-696 (1980).

60. Mahmoodinia, M. et al. Structural and electronic properties of the Pt-n-PAH complex $(\mathrm{n}=1,2)$ from density functional calculations. Phys. Chem. Chem. Phys. 16, 18586-18595 (2014).

61. Mahmoodinia, M., Astrand, P. O. \& Chen, D. Influence of carbon support on electronic structure and catalytic activity of pt catalysts: binding to the $\mathrm{CO}$ Molecule. J. Phys. Chem. C 120, 12452-12462 (2016).

62. Hummers, W. S. \& Offeman, R. E. Preparation of graphitic oxide. J. Am. Chem. Soc. 80, 1339-1339 (1958)

63. King, J. S. et al. Ultralow loading Pt nanocatalysts prepared by atomic layer deposition on carbon aerogels. Nano Lett. 8, 2405-2409 (2008).

64. Zhou, Y., King, D. M., Liang, X. H., Li, J. H. \& Weimer, A. W. Optimal preparation of $\mathrm{Pt} / \mathrm{TiO} 2$ photocatalysts using atomic layer deposition. Appl. Catal. B Environ. 101, 54-60 (2010).

65. Hamalainen, J., Puukilainen, E., Sajavaara, T., Ritala, M. \& Leskela, M. Low temperature atomic layer deposition of noble metals using ozone and molecular hydrogen as reactants. Thin Solid Films 531, 243-250 (2013).

66. Delley, B. Hardness conserving semilocal pseudopotentials. Phys. Rev. B 66 155125 (2002).

67. Perdew, J. P., Burke, K. \& Ernzerhof, M. Generalized gradient approximation made simple. Phys. Rev. Lett. 77, 3865-3868 (1996).

68. Delley, B. From molecules to solids with the DMol(3) approach. J. Chem. Phys. 113, 7756-7764 (2000)

69. Jiang, H. L. \& Xu, Q. Catalytic hydrolysis of ammonia borane for chemical hydrogen storage. Catal. Today 170, 56-63 (2011).

\section{Acknowledgements}

This work was supported by the National Natural Science Foundation of China (21473169, 21673215, 21533007, and 21233007), Innovative Research Groups of the National Natural Science Foundation of China (11621063), the One Thousand Young Talents Program under the Recruitment Program of Global Experts, the Young Scientists Fund of the National Natural Science Foundation of China (11404314), Anhui Provincial Natural Science Foundation (1708085MA06), and the Fundamental Research Funds for the Central Universities (WK2060030017). The calculations were performed on the supercomputing system in USTC-SCC and Guangzhou-SCC. We gratefully thank the BL14W1 beamline at the Shanghai Synchrotron Radiation Facility (SSRF), China.

\section{Author contributions}

J.L. conceived the idea and designed the experiments. H.Y. performed catalyst synthesis and catalytic performance evaluations. Y.L. performed the STEM measurements. S.W. Z.S., H.C., W.L., and T.Y. performed the XAFS measurements. W.Z., H.W., and J.Y. performed the DFT calculations. C.W., J.L., and X.H. assisted catalyst characterization and catalytic performance tests. J.L. wrote the manuscript. All the authors contributed and commented on the manuscript. H.Y. and Y.L. contributed equally to this work.

\section{Additional information}

Supplementary Information accompanies this paper at 10.1038/s41467-017-01259-z.

Competing interests: The authors declare no competing financial interests.

Reprints and permission information is available online at http://npg.nature.com/ reprintsandpermissions/ 
Publisher's note: Springer Nature remains neutral with regard to jurisdictional claims in published maps and institutional affiliations.

(c) (i) Open Access This article is licensed under a Creative Commons Attribution 4.0 International License, which permits use, sharing, adaptation, distribution and reproduction in any medium or format, as long as you give appropriate credit to the original author(s) and the source, provide a link to the Creative Commons license, and indicate if changes were made. The images or other third party material in this article are included in the article's Creative Commons license, unless indicated otherwise in a credit line to the material. If material is not included in the article's Creative Commons license and your intended use is not permitted by statutory regulation or exceeds the permitted use, you will need to obtain permission directly from the copyright holder. To view a copy of this license, visit http://creativecommons.org/ licenses/by/4.0/.

(C) The Author(s) 2017 